\title{
Influence of Adhesive Wear and Thermal Degradation on the Frictional Characteristics of Paper-Based Friction Materials: A Comparative Study
}

\author{
Agusmian Partogi Ompusunggu, ${ }^{1}$ Paul Sas, ${ }^{2}$ and Hendrik Van Brussel ${ }^{2}$ \\ ${ }^{1}$ Flanders' Mechatronics Technology Centre (FMTC), Celestijnenlaan 300D, 3001 Heverlee, Belgium \\ ${ }^{2}$ Division PMA, Department of Mechanical Engineering, Katholieke Universiteit Leuven (KU Leuven), Celestijnenlaan 300B, \\ 3001 Heverlee, Belgium
}

Correspondence should be addressed to Agusmian Partogi Ompusunggu; agusmian.ompusunggu@fmtc.be

Received 22 October 2012; Accepted 20 November 2012

Academic Editors: M. Kuciej and Y. Lu

Copyright @ 2013 Agusmian Partogi Ompusunggu et al. This is an open access article distributed under the Creative Commons Attribution License, which permits unrestricted use, distribution, and reproduction in any medium, provided the original work is properly cited.

\begin{abstract}
This paper discusses the effects of adhesive wear and thermal degradation on the dry frictional characteristics of paper-based friction materials against steel material. Some commercial paper-based friction materials typically used for clutch applications were subjected to adhesive wear and thermal degradation and the dry frictional characteristics were then measured at different states on a rotational tribometer. The experimental results reveal that both adhesive wear and thermal degradation have opposite effects on the frictional characteristics, where the static and kinetic coefficients of friction increase due to adhesive wear but decrease due to thermal degradation.
\end{abstract}

\section{Introduction}

Paper-based materials have gained popularity as lining materials of the friction discs of transmission clutches because of their favorable properties such as high coefficient of friction (COF), stable friction characteristics, and low production cost $[1,2]$. These materials are porous composites, basically containing some ingredients such as fiber, solid lubricant, and friction modifiers; which are all saturated and cured at certain pressure and temperature, with the thermosetting resin acting as a binder [3].

After the first introduction of paper-based material for automatic transmission clutches, asbestos fibers were widely used as the main ingredient. However, it was found later on that the airborne asbestos fibers can cause serious health problems $[5,6]$. As a consequence, the use of the asbestos fiber has been restricted since the 1970. The restriction was first applied in the USA and then across the globe [7]. Nowadays, asbestos fibers are no longer used for paper-based friction materials [8]. In general, the composition of modern paper-based friction materials is visually shown in Figure 1.

To obtain as high COF as possible, a paper-based material has to be designed with following specifications: (i) suffciently high porosity and resilience as recommended in [912] and (ii) plateaued (stratified) surface [13, 14]. Here, a plateaued surface is referred to as a surface having a negatively skewed asperity heights distribution. High porosity implies that the clutch lubricant can flow into the friction materials and expand the sliding area where boundary lubrication is dominant, resulting in a higher kinetic $\mathrm{COF} \mu_{k}$. Furthermore, a plateaued surface significantly contributes to larger microcontact area, that is, real contact area, which consequently results in higher static COF $\mu_{s}$. This micro contact area is attributed with the discrete contact spots area formed by the contacting "asperity" summits. According to the Oxford Dictionary, the word "asperity" is defined as irregularities of surface, roughness or harshness. A typical surface profile of a new paper-based friction material is shown in Figure 2 


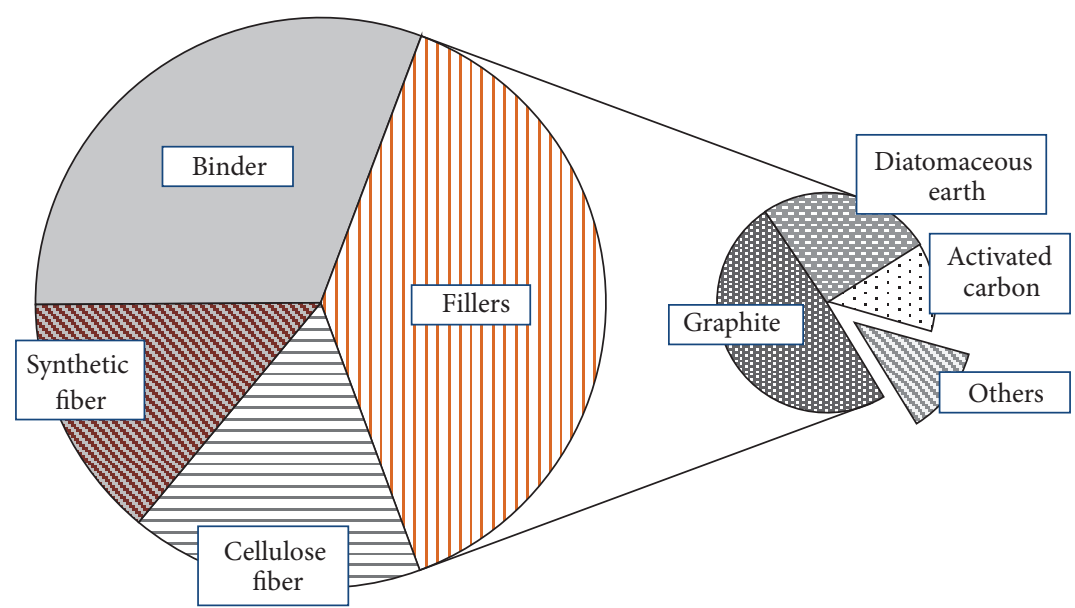

FIGURE 1: Schematic composition of a modern paper-based friction material, reproduced from [4].

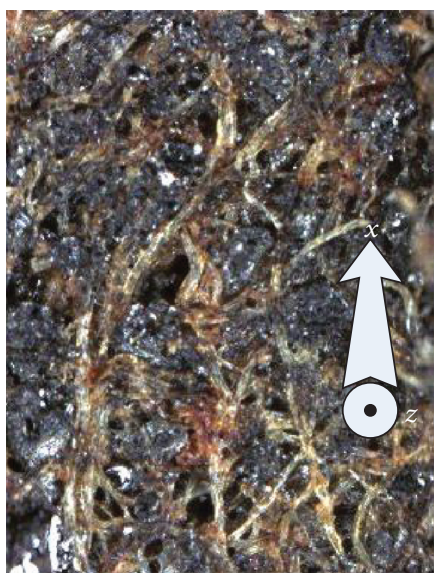

(a)

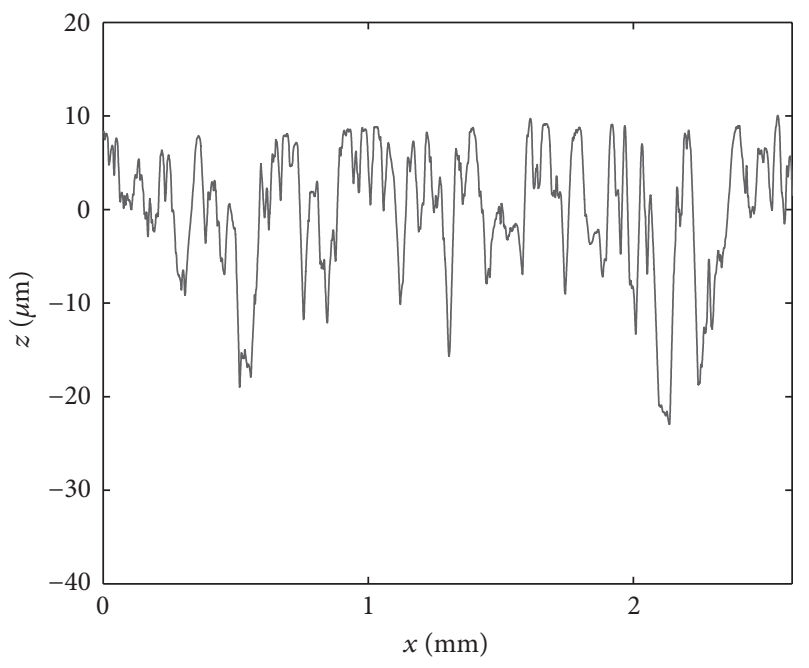

(b)

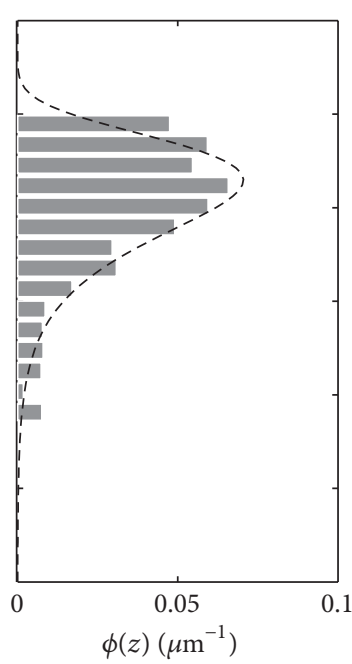

Figure 2: (a) Optical image of a fresh paper-based friction material and (b) the typical profile exhibiting a plateaued surface. Note that the surface profile is measured along the sliding direction as indicated by the white arrow.

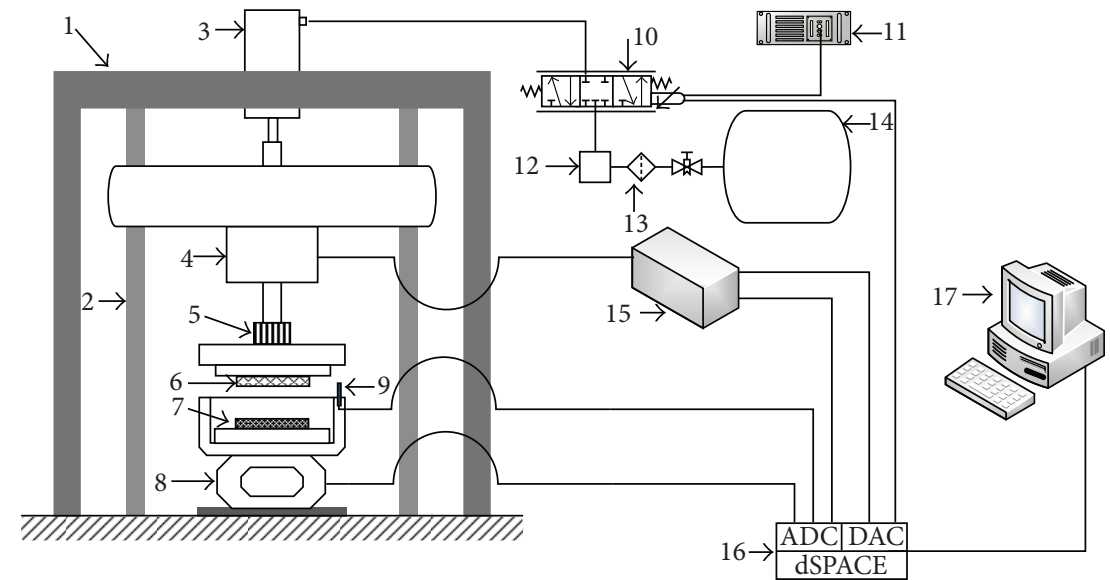

FIGURE 3: Schematic view of the tribometer. 


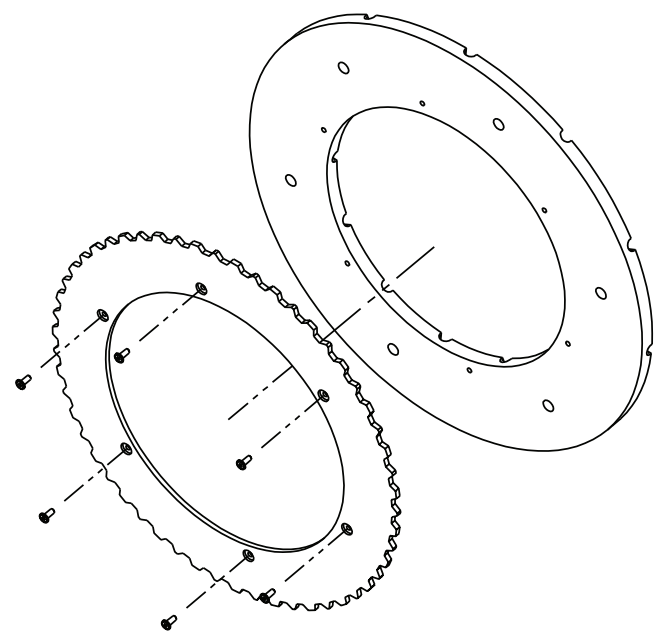

(a)

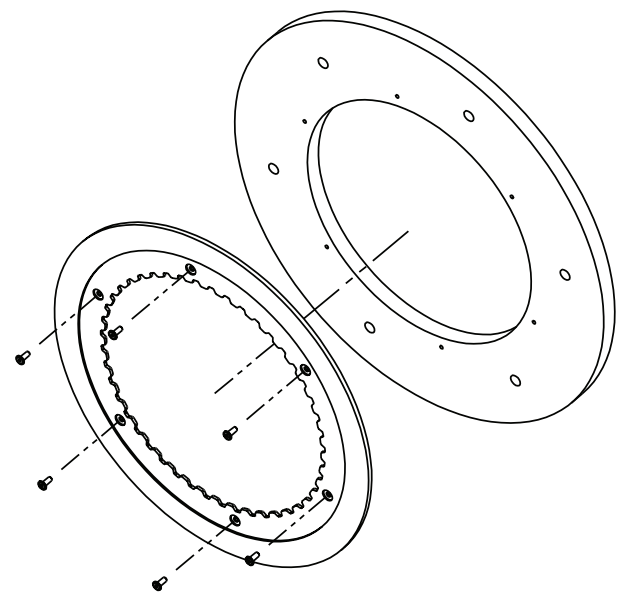

(b)

FIGURE 4: Configuration of (a) separator disc and (b) friction disc with respect to the corresponding holders.

One can notice from the figure that the asperity heights distribution $\phi(z)$ is asymmetric, which cannot be accurately approximated with the Gaussian distribution.

Significant improvements in the performance and durability of such a material have been achieved in recent years through (i) the development of different types of fibers such as carbon fiber, aramid fiber (e.g., Kevlar), ceramic fiber, and cellulose fiber $[8,15]$, resins [16, 17], and fillers [18]; (ii) the optimization of the combination and content ratio of the ingredients $[4,17]$. The performance and composition of a resin has a considerable impact on the mechanical properties of the friction material $[16,17]$. In order to have a paper-based material with optimal mechanical properties, heat resistance, friction, and wear performance, Fei et al. [17] suggest that the composition of the resin in the material should be between 35 and $40 \%$.

Clutches are designed to expose a certain behavior in the beginning of their lifetime in order to fulfill some required performance for transmissions. As an illustration, a clutch should be able to transmit a certain power from the engine to the wheels under a smooth and fast engagement with minimal shudder. However, due to the unavoidable degradation, the frictional characteristics change, thus altering its initial performance. Moreover, the progression of the degradation may lead to poor frictional behavior causing less power transmission, severe shudder, and an unfavorable engagement process. Eventually, when the degradation nearly reaches the catastrophic stage, the clutch frictional behavior becomes severely poor and in addition the clutch is not functioning any longer as it should be, leading to the total breakdown of the vehicles. Before this undesired condition occurs, a maintenance action therefore needs to be scheduled for the replacement of the friction discs such that the initial performance of clutches can be maintained.

As reported in the literature, adhesive wear and thermal degradation are listed as the main degradation sources of paper-based materials used in clutch applications. In practice, both degradation sources inevitably occur simultaneously, leading to a well-known phenomenon which is called glazing [13]. As a result of this phenomenon, the surface of the friction material looses its porosity (i.e., the surface porosity decreases due to blocking of deposition of debris particles), becomes smoother, and appears glazed [19]. Many intensive studies have been carried out to characterize the frictional characteristics of paper-based friction material due to the degradation [12, 19-22]. However, the respective influences of adhesive wear and thermal degradation occurring in the material on the frictional characteristics during its lifetime still remain unclear and are subject to further investigation. Several researchers $[14,23]$, by ignoring the thermal degradation effect, have attempted to understand the adhesive wear effect on the contact properties of a paper-based material during the run-in tests, namely, the real contact area and the number of asperities making contact. They reported that the two contact parameters increase as the wear progresses. Nevertheless, the effects of adhesive wear occurring in the material on the frictional characteristics need to be further investigated.

This paper aims at understanding the respective influence of the degradation sources occurring in paper-based materials, that is, adhesive wear and thermal degradation, on the frictional characteristics. A profound understanding of the influence is essential for predicting the lifetime behavior of mechanical components equipped with paperbased materials as the lining materials, such as clutches. The gained knowledge can be further employed to establish the relationship between the health status and the dynamic behavior of the components. In this way, the state of a paperbased material can be predicted from the dynamic behavior of the component.

The remainder of this paper is organized as follows. After discussing the motivation and objective of this paper, the methodology to investigate the influences and the experimental aspects are proposed in Section 2. Results obtained from the study are then presented and discussed in Section 3. Finally, some conclusions drawn from the study, that can be a basis for future work, are given in Section 4. 


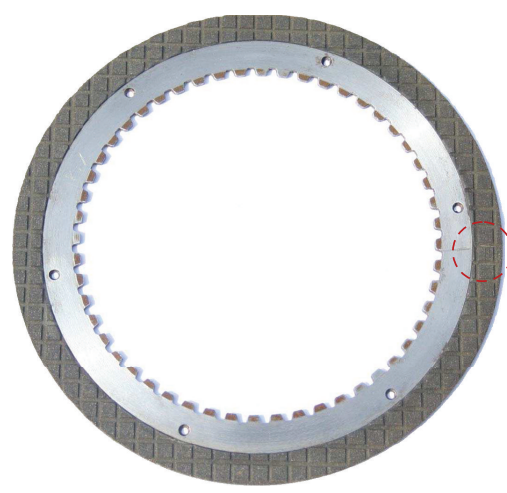

(a)

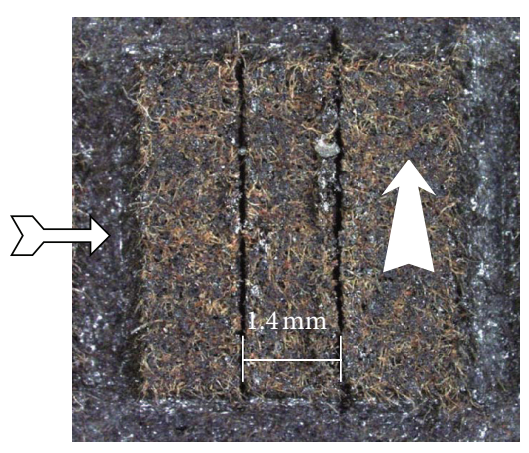

(b)

Figure 5: (a) A modified friction disc and (b) the reserved area for the surface topography measurement.

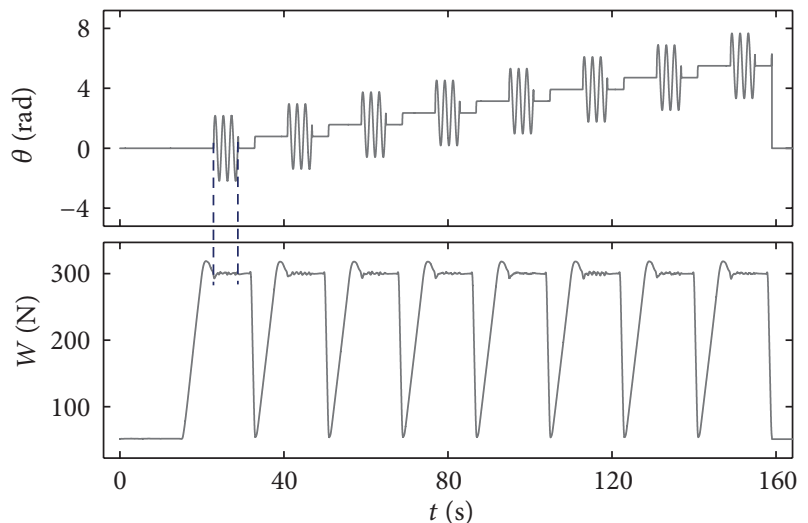

FIGURE 6: Typical relative motion profile $\theta$ between the friction and separator disc and the normal load profile $W$.

\section{Methodology and Experiment}

To investigate the influences of adhesive wear and thermal degradation occurring in paper-based material on the frictional characteristics, in this study, some commercial friction discs which are typically used for clutch applications are employed. Note that all the tests, comprising wear and thermal degradation inducements and friction measurements, were carried out in unlubricated (dry) environment. As the surface profile can be presumably affected by the two mechanisms, thus, it is important to evaluate the topography of the materials at different states. Here, the surface profiles are measured and evaluated by using a talysurf profilometer.

This section first discusses the used rotational tribometer. Afterwards, some details concerning the used materials and preparation prior to perform the tests are discussed. Finally, the experimental procedures carried out in the study are proposed.

2.1. Rotational Tribometer Setup. The tribometer used in this study was originally developed by the previous researcher [24] at the Department of Mechanical Engineering of KU

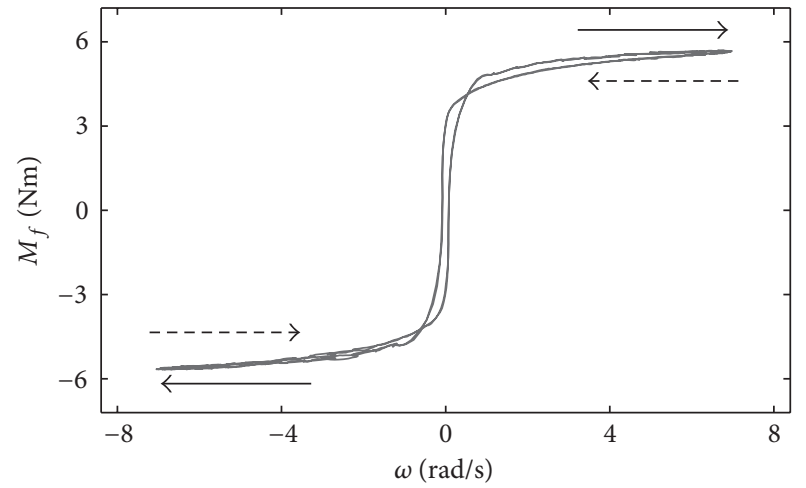

(a)

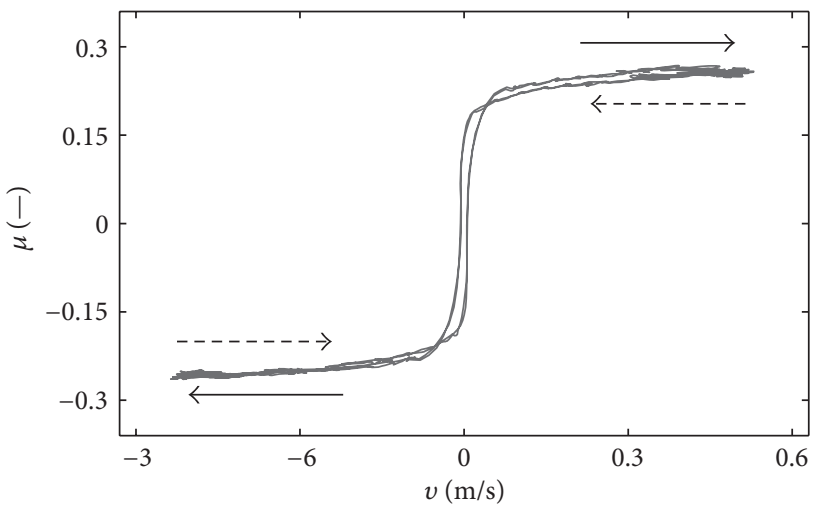

(b)

Figure 7: Typical friction characteristics of a new paper-based material in dry environment. Note that the solid and the dashed arrows, respectively, denote acceleration and deceleration.

Leuven with the main objective of accurate characterization of the friction phenomena occurring between two flat discs that slide past each other rotationally, either in dry or wet (lubricated) environment. Physical quantities that can be measured on the tribometer are torque, normal load, normal displacement, angular displacement, angular velocity, and temperature. 


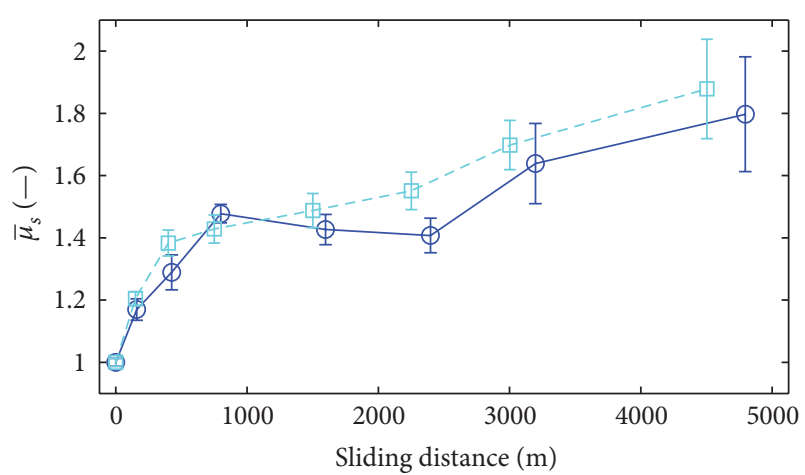

(a)

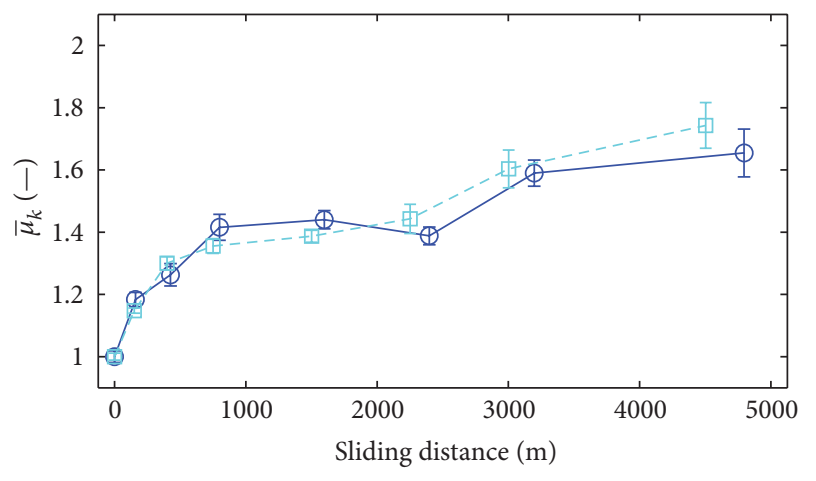

○- Sample A1

$-\boxminus-$ Sample B1

(b)

FIGURE 8: Evolution of the normalized static and kinetic COFs obtained from the wear tests.

For this present work, a modification has been applied to the tribometer, namely, adding a pneumatic actuator system that enables one to apply a normal load accurately and to automate the measurements. As shown in Figure 3, the tribometer setup basically consists of the following main components: (1) frame fixed to the ground, (2) vertical guide ways aligning the upper and lower part, (3) shaker generating either a static or dynamic load, (4) direct drive motor with a built-in high-resolution encoder of 163,840 pulses/revolution, (5) flexible coupling ensuring that the contacting surfaces are aligned under load to establish an uniform pressure distribution across the whole contact area, (6) friction disc attached to the upper holder, (7) separator disc attached to the lower holder, (8) three strain gage-based dynamometers (only one of them is shown) assembled to a six DOF measuring table, (9) three capacitive displacement sensors (only one shown) placed at different positions (120 degrees), (10) proportional pneumatic valve, (11) DC voltage supply, (12) air pressure regulator, (13) air filter, (14) pressurized air source, (15) motor drive, (16) dSPACE interface, and (17) personal computer (PC).

This fully instrumented tribometer can allow us to accurately characterize both presliding and sliding (gross sliding) frictions. In addition, the contact properties, such as tangential and normal contact stiffnesses, which are beyond
TABLE 1: Overview of the friction discs used in the investigation.

\begin{tabular}{lccc}
\hline Product & $\begin{array}{c}\text { Inner diameter } d_{i} \\
(\mathrm{~mm})\end{array}$ & $\begin{array}{c}\text { Outer diameter } d_{o} \\
(\mathrm{~mm})\end{array}$ & $\begin{array}{c}\text { Mean diameter } d_{m} \\
(\mathrm{~mm})\end{array}$ \\
\hline $\mathrm{A}$ & 136 & 160 & 148 \\
$\mathrm{~B}$ & 130 & 148 & 139 \\
\hline
\end{tabular}

the scope of this current work, can also be identified. For presliding friction identification, a small relative displacement between the friction and separator disc is imposed, where the amplitude of the displacement is selected such that only a microslip is observed. On the tribometer, this small displacement can be achieved due to the combination of the direct drive motor and the high-resolution encoder. Additionally, the motor can be controlled either in position or velocity mode with a proportional-derivative (PD) control. At the nominal load, it can rotate up to the maximum angular velocity of $4.8 \pi \mathrm{rad} / \mathrm{s}$. For sliding friction identification, a large relative displacement between the friction and the separator disc is imposed such that a gross sliding can be observed.

The six-DOF measuring table on the tribometer is employed to measure the friction torque and the applied normal load. Based on the design specifications, the maximum normal load and torque which are recommended to be applied on the table are, respectively, $1290 \mathrm{~N}$ and $15 \mathrm{Nm}$. To generate the static normal load, pressurized air is applied to the shaker, which is actuated by the valve using a closed-loop proportional-integral-derivative (PID) controller. During the tests, all the acquired data are discretized with sampling frequency of $400 \mathrm{~Hz}$ and filtered by a low-pass filter with the cut-off frequency of $100 \mathrm{~Hz}$ in order to discard the high frequency and aliasing noise.

2.2. Materials. Four commercial friction discs made by two different anonymous manufactures (i.e., two discs of each product) and one separator disc, which all are provided by our industrial partner, are employed in this study. Prior to the tests, all the friction and separator discs are machined such that they can be attached to the corresponding holders. On one side of each friction disc, the lining material is completely removed, while on the other side, the inner diameter $d_{i}$ of the lining materials is enlarged and the outer diameter $d_{o}$ is kept intact. In this way, the apparent contact area is reduced so that the apparent pressure is higher. Six counter bores are made on each friction and separator disc for attaching them onto the corresponding holders with bolts; see Figure 4 .

Table 1 lists some details of the friction discs used in the investigation. All the friction discs (products A and B) are paper-based type and have the same groove pattern, that is, waffle groove type. Approximately, one-third area of a waffle block (i.e., width of $\sim 1.4 \mathrm{~mm}$ ) of each friction disc is reserved for surface topography measurement as illustrated in Figure 5.

2.3. Experimental Procedure. Prior to perform either a wear or a thermal test, the surface profile of each sample is 


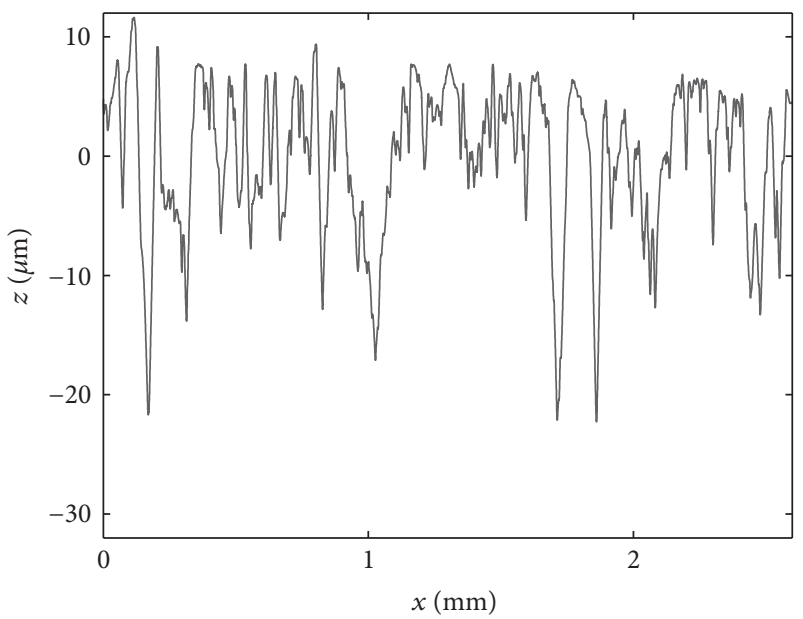

(a)

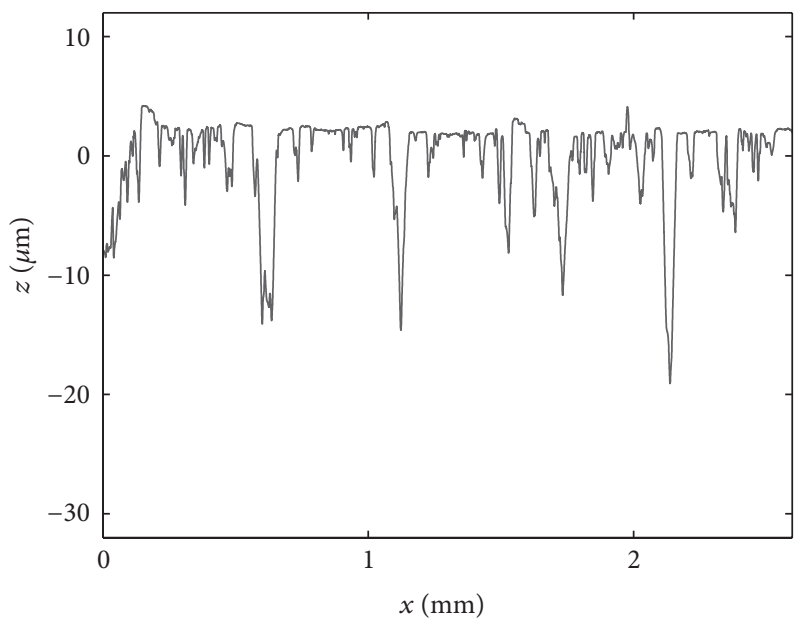

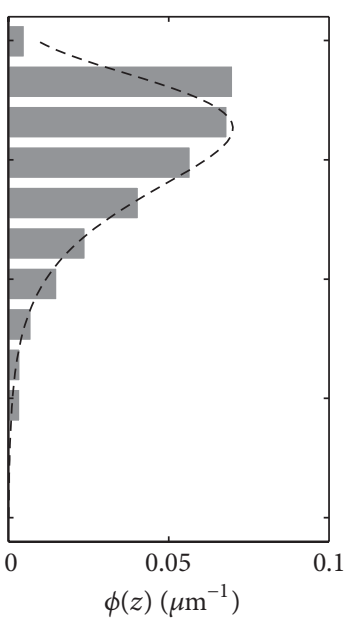

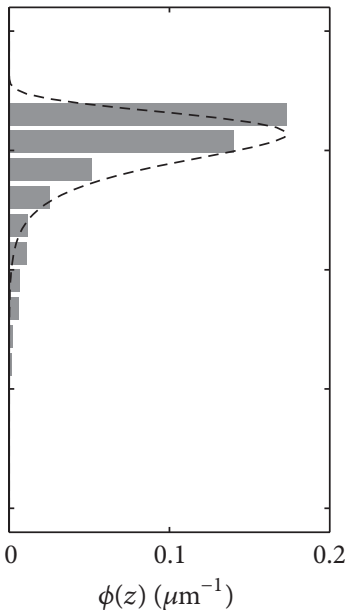

(b)

FIGURE 9: Change of the surface topography of a representative friction disc (a) before and (b) after the wear test.

measured on the reserved area along the sliding direction as indicated by the white arrow in Figure 5. In order to have representative results, the topography measurements on the reserved area are carried out at four different radial positions. It is remarkable to mention that no intermediate surface profile measurement was performed during the wear test since the effect of adhesive wear on the surface profile is fairly well understood. Jeng and Gao [25] show that the roughness and the skewness of the surface profile of some materials decrease with the progression of adhesive wear. Nyman et al. [26] confirm such findings on sintered bronze materials which are used in limited slip differential clutch applications. Instead, intermediate surface profile measurement was performed in the thermal test since the effect on the surface profile, according to the authors' knowledge, is not well understood.

2.3.1. Inducement of Adhesive Wear and Thermal Degradation. Adhesive wear is induced into a friction disc by sliding it against a separator disc at a constant normal load of $200 \mathrm{~N}$ (i.e., the apparent pressures corresponding to this load for products $\mathrm{A}$ and $\mathrm{B}$ are $0.36 \times 10^{5} \mathrm{~Pa}$ and $0.51 \times 10^{5} \mathrm{~Pa}$, resp.) and a constant angular velocity of $12 \mathrm{rad} / \mathrm{s}$ during a predefined sliding time interval $t_{\text {slide. Since a wear test can }}$ dissipate heat, an air fan was used during the test to forcibly cool the tribometer in order to avoid the temperature increase that may introduce unwanted thermal degradation in the samples. Once the predefined time interval is accomplished, the motor is switched off and the sample is unloaded for a while. Consecutively, the friction torque between the friction and separator disc is measured following the procedure that will be described in Section 2.3.2. This test sequence is repeated until the predefined total sliding time $\tau_{\text {slide }}$ is completed. Given $\omega_{\text {slide }}$ and $\tau_{\text {slide }}$, the total sliding distance $X_{\text {slide }}$ of each sample can thus be computed. Note that the total sliding distance $X_{\text {slide }}$ is computed with respect to the center of the lining material, that is, $X_{\text {slide }}=d_{m} / 2 \times$ $\omega_{\text {slide }} \times \tau_{\text {slide }}$, where $d_{m}=\left(d_{i}+d_{o}\right) / 2$ denotes the mean 


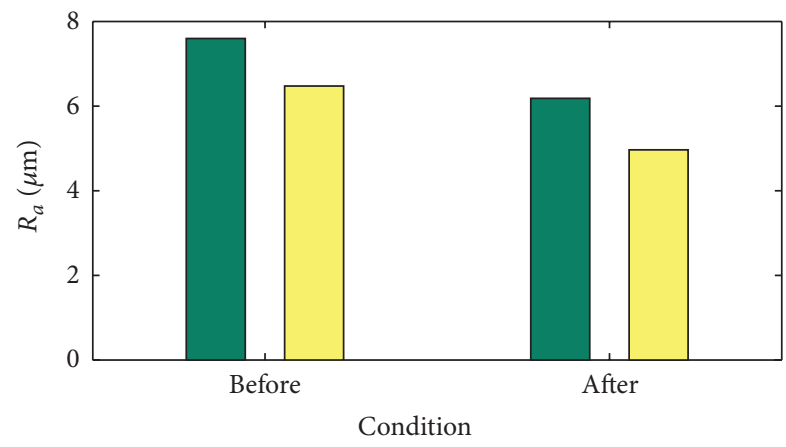

(a)

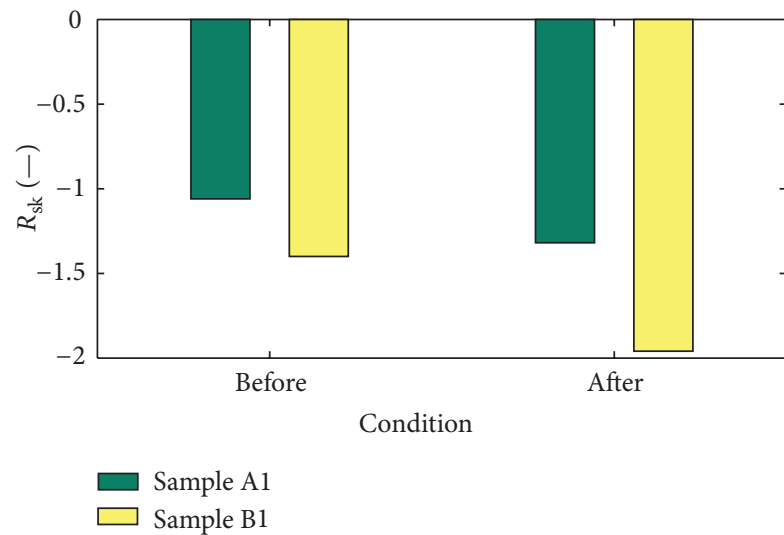

(b)

FIGURE 10: Topography parameters, $R_{a}$ and $R_{\mathrm{sk}}$, measured before and after the wear tests. At each state, both parameters are the averaged values of four measurements at different locations.

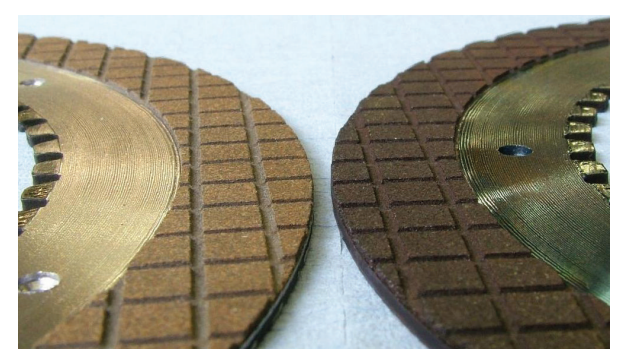

FIGURE 11: Photographs of the fresh (left) and thermally degraded friction discs (right). The degraded friction disc results from heating up an identical fresh disc in an oven at $200^{\circ} \mathrm{C}$ for 24 hours in dry environment.

TABLE 2: Overview of the wear and thermal tests.

\begin{tabular}{llll}
\hline Test mode & \multicolumn{1}{c}{ Comment } & \multicolumn{2}{c}{ Tested sample } \\
\hline Wear test & $\tau_{\text {slide }}=90$ minutes & A1 & B1 \\
Thermal test & $\tau_{\text {heating }}=60$ hours & A2 & B2 \\
\hline
\end{tabular}

diameter given in Table 1. According to Table 2, the total sliding distances of sample types A and B are $4.795 \mathrm{~km}$, and $4.503 \mathrm{~km}$, respectively.

Different from the wear test, thermal degradation is induced into a friction disc by heating it up in an oven under

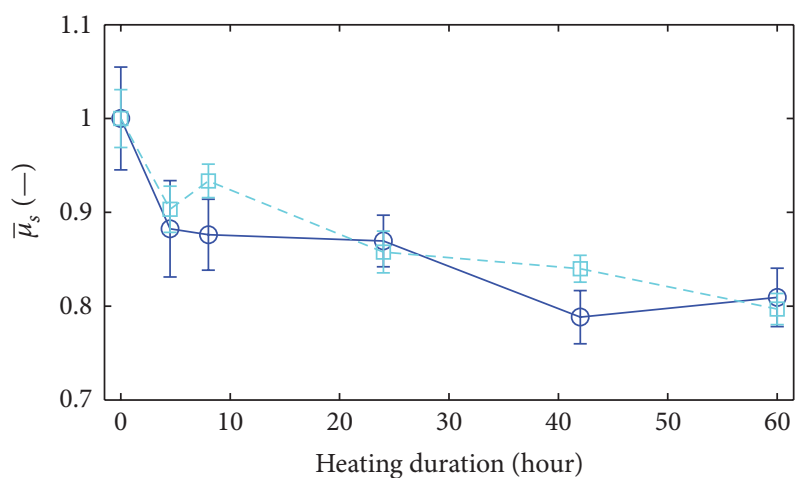

(a)

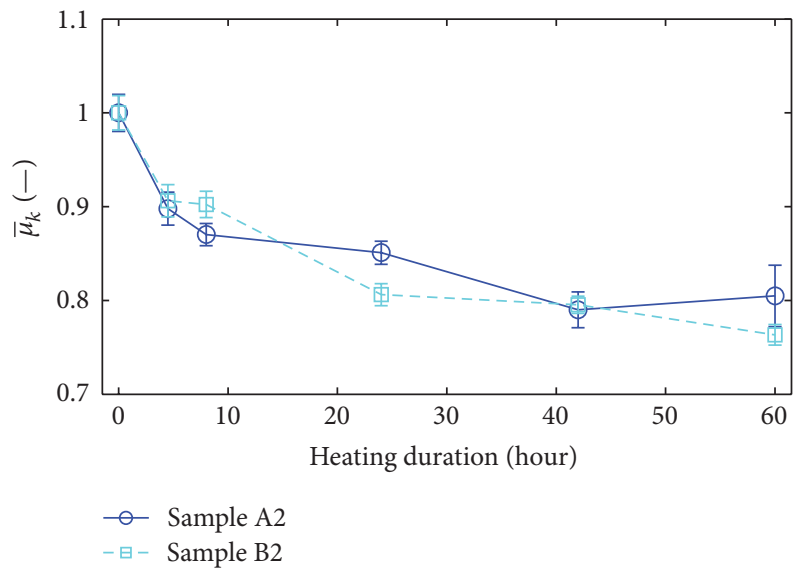

(b)

FIgURE 12: Evolution of the normalized static and kinetic COFs obtained from the thermal tests.

a controlled temperature $\left(200^{\circ} \mathrm{C}\right)$ for a predefined heating time $t_{\text {heating. }}$. After the $t_{\text {heating }}$ is reached, the sample is taken out from the oven and then naturally cooled with air until it reaches the room temperature. Once the equilibrium state is reached, the surface profile measurement is carried out and the sample is then reinstalled on the tribometer for the friction measurement according to the procedure described in Section 2.3.2. These all steps are repeated for each sample until the predefined total heating time $\tau_{\text {heating }}$ is attained. It should be noticed here that the heating time is predetermined based on our exploration on some friction discs.

2.3.2. Friction Measurement Procedure. The frictional characteristics of each friction material at a certain state are measured at room temperature $\left(\sim 20^{\circ} \mathrm{C}\right)$ by imposing a sinusoidal relative motion between the friction disc and the separator disc. In this way, the effect of accelerated and decelerated motions on the friction characteristics can be evaluated.

In this study, the amplitude and frequency of the sinusoidal motion are chosen to be 2 rad and $0.5 \mathrm{~Hz}$, respectively. The frictional characteristics are investigated at one normal load of $300 \mathrm{~N}$ and eight different angular positions. For products $\mathrm{A}$ and $\mathrm{B}$, this normal load corresponds to the apparent contact pressures of $0.54 \times 10^{5} \mathrm{~Pa}$ and $0.76 \times 10^{5} \mathrm{~Pa}$, respectively. Figure 6 illustrates the position of the friction disc with 


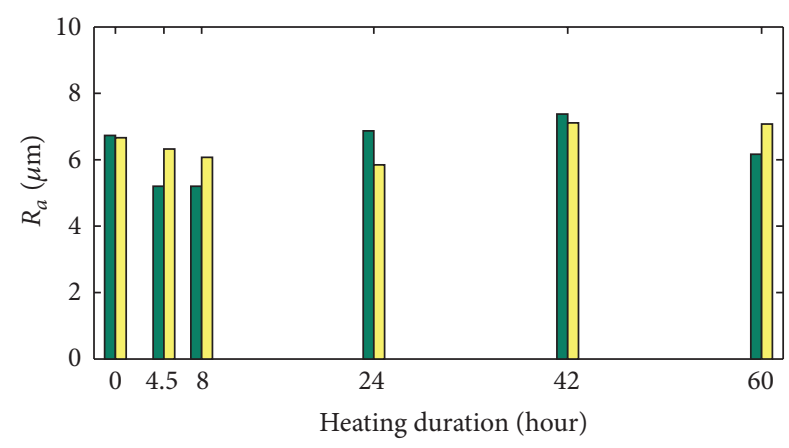

(a)

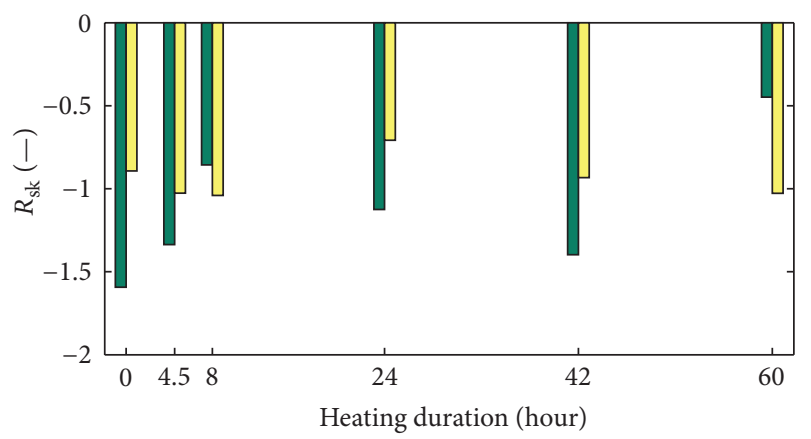

Sample A2

Sample B2

(b)

FIGURE 13: Evolution of the topographical parameters, $R_{a}$ and $R_{\mathrm{sk}}$, with the progression of thermal degradation.

respect to the separator disc for the friction characterization purpose. As seen in the figure, the sinusoidal motion is imposed when the applied normal load $W$ reaches the steady state (the time interval between the two vertical dashed lines).

\section{Results and Discussion}

Figure 7 shows typical plots of the friction torque $M_{f}$ versus the angular velocity $\omega$ and the COF $\mu$ versus the sliding velocity $v$ (i.e., $v=d_{m} \omega / 2$ ) measured on the tribometer. One can see that both friction curves are nearly symmetric with respect to the origin, that is, point symmetry, and exhibit the frictional lag phenomenon where the friction torque or COF measured during acceleration (solid arrow) is larger than that measured during deceleration (dashed arrow) [27, 28]. Note that the negative COF implies that the measured friction torque is negative.

The COF $\mu$ is computed according to the following equation [22]:

$$
\mu=\frac{3 M_{f}\left(r_{o}^{2}-r_{i}^{2}\right)}{2 W\left(r_{o}^{3}-r_{i}^{3}\right)},
$$

where $r_{i}=d_{i} / 2$ and $r_{o}=d_{o} / 2, M_{f}$ is the measured friction torque, and $W$ is the applied load. Note that the equation is derived under the assumption that the pressure across the contact surface is uniform. The derivation of this equation is shortly discussed in the appendix.

The $\mu-v$ curve as shown in Figure $7(\mathrm{~b})$ is often used to describe the frictional characteristics of a tribological system. As a practical example in automatic transmissions, the curve slope at low velocity has been widely accepted to be responsible for the presence of shudder. The more positive the slope is, the less shudder is generated in the transmissions. Therefore, the $\mu-v$ curve with a positive slope is well known to have an antishudder property.

Figure 7 shows the frictional characteristic of a fresh sample measured in unlubricated (dry) environment. It is evident from the figure that the tested sample has an antishudder property. This uncommon dry friction characteristic is possibly due to the shear mechanism activated in the pseudoresin-resin contact occurring in paper-based materials as hypothesized by Ingram et al. in [29].

In this paper, two quantities, namely, the static COF $\mu_{s}$ and kinetic $\mathrm{COF} \mu_{k}$, are considered as parameters representing the frictional characteristics. The $\mu_{s}$ is defined here as the averaged of the maximum COF when the absolute sliding velocity $|v|$ ranges from 0.01 to $0.1 \mathrm{~m} / \mathrm{s}$, while the $\mu_{k}$ is defined as the mean COF when the $|v|$ ranges from 0.35 to $0.45 \mathrm{~m} / \mathrm{s}$. Mathematically speaking, the static $\mathrm{COF} \mu_{s}$ and the kinetic COF $\mu_{k}$ can be expressed as follows:

$$
\mu_{s}=\frac{\mu_{s}^{+}+\mu_{s}^{-}}{2},
$$

with

$$
\begin{gathered}
\mu_{s}^{+}=\max (\{\mu(v): 0.01<v<0.1\}), \\
\mu_{s}^{-}=\max (\{\mu(v):-0.1<v<-0.01\}), \\
\mu_{k}=\frac{1}{2\left(v_{2}-v_{1}\right)}\left[\int_{v_{1}}^{v_{2}} \mu d v+\left|\int_{-v_{1}}^{-v_{2}} \mu d v\right|\right],
\end{gathered}
$$

where $v_{1}=0.35$ and $v_{2}=0.45$.

Since the evolution of the static $\mathrm{COF} \mu_{s}$ and kinetic COF $\mu_{k}$ is of interest in this study, it is thus convenient to normalize these two quantities with respect to their reference values ( $\mu_{s}^{\text {ref }}$ and $\mu_{k}^{\text {ref }}$ ) which are measured at initial condition. The normalized static $\operatorname{COF} \bar{\mu}_{s}$ and normalized kinetic $\operatorname{COF} \bar{\mu}_{k}$ are expressible as

$$
\bar{\mu}_{s}=\frac{\mu_{s}}{\mu_{s}^{\text {ref }}}
$$

and similarly

$$
\bar{\mu}_{k}=\frac{\mu_{k}}{\mu_{k}^{\mathrm{ref}}} .
$$

3.1. Influence of Adhesive Wear. Figure 8 shows the evolution of the normalized static $\mathrm{COF} \bar{\mu}_{s}$ and normalized kinetic COFs $\bar{\mu}_{k}$ in function of the sliding distance. In general, one can see that the two normalized COFs increase with the progression of adhesive wear.

The increasing COFs shown in Figure 8 can be explained as follows. During adhesive wear process, a certain amount 

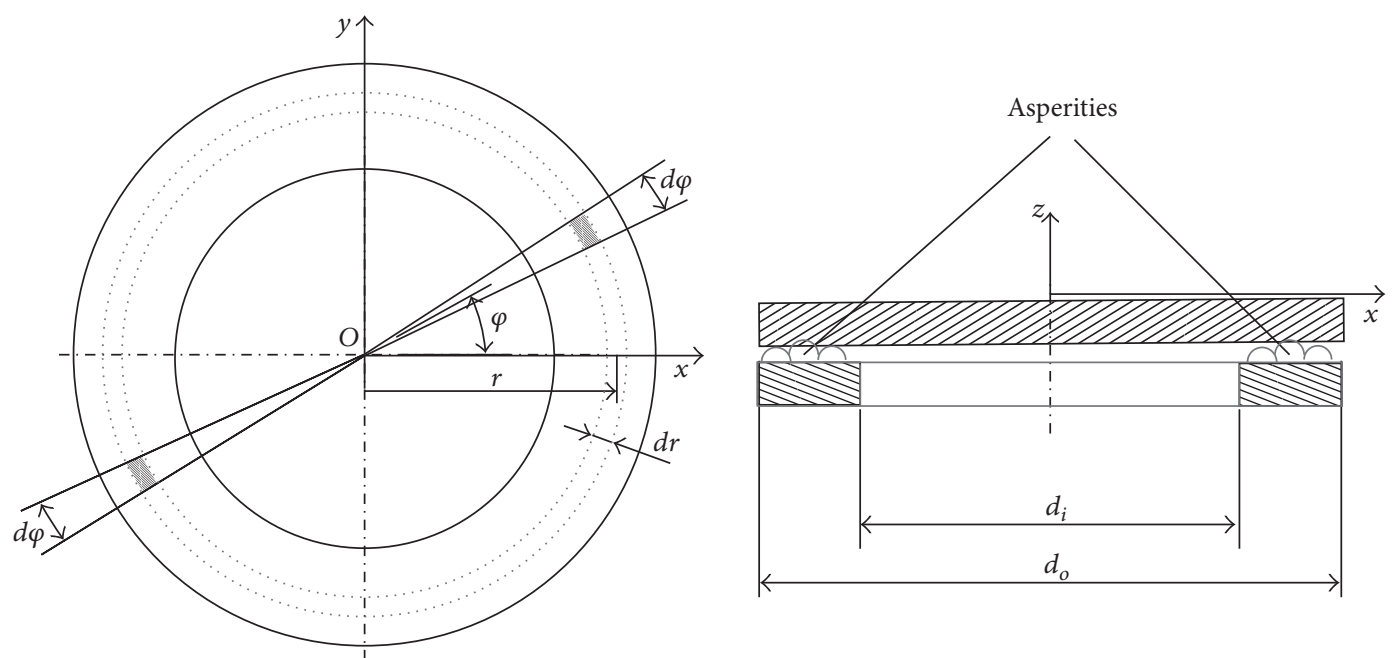

FIGURE 14: Schematic illustration of the contact of two (nominally flat) discs.

of debris particles is produced because of the loss of material in the contact regions. As wear progresses, the amount of material loss increases. Consequently, the contact regions (peaks) become flatter leading to the alteration of the surface topography, as can be seen in Figure 9. One can see in the figure that the surface roughness $R_{a}$ decreases and the skewness $R_{\text {sk }}$ becomes more negative. Qualitatively similar change on the surface profile is also observed on another sample as seen in Figure 10.

In the macroscopic scale, decreasing $R_{a}$ and $R_{\mathrm{sk}}$ indicates that the surface becomes smoother and more plateaued. On a microscopic scale, these reductions can be translated into the fact that the real contact area $A_{r}$ and the number of asperities making contact $N_{\text {ac }}$ increase in size, as experimentally investigated both in dry and lubricated conditions [14, 23]. Hence, at given normal load, the $A_{r}$ and $N_{\text {ac }}$ of a worn surface are larger than those of a fresh surface. The nature of the contact between the two contacting surfaces will change due to the alteration of both micro contact properties $\left(A_{r}\right.$ and $N_{\text {ac }}$ ), thus changing the friction torque or COF. By assuming that the friction material properties remain constant, it is therefore reasonable to conclude that the increase of the COFs is caused by the increase of the $A_{r}$ and $N_{\mathrm{ac}}$.

3.2. Influence of Thermal Degradation. Visually, the effect of thermal degradation on one of the samples (i.e., sample A2) can be seen in Figure 11. Due to a relatively high temperature during a certain duration, the material is presumably oxidized homogeneously through the network of the fibrous composite which is evident from the color change.

Figure 12 shows the evolution of the normalized static and kinetic COFs measured at room temperature after different heating durations. In contrast to the influence of adhesive wear, the static and kinetic COFs tend to decrease with the progression of thermal degradation.

The evolutions of the topography parameters of the samples A2 and B2 during the thermal tests are shown in Figure 13. As is obvious in the figure, there is no notably systematic change of the surface topography due to thermal degradation. This implies that the change of the surface topography at the predefined temperature has no strong correlation to the reduction of the COFs that appears to be a systematic change. It is likely that the change of the surface topography due to thermal degradation at this particular temperature has minor impact in changing the COFs.

Based on the observation of such findings, the systematic reduction of the static and kinetic COFs revealed in the thermal tests is believed to be predominantly caused by the change of the structure and properties of the material due to high temperature. Such a hypothesis can be explained as follows. As composites, the structure and the mechanical properties of paper-based materials are strongly determined by the composition ratio of the resin as a binder [17]. During the curing process when a paper-based material is manufactured, the resin is hardened, which cannot be melted and reshaped. The resin in the friction material, for example, phenolic resin, is inherently quite brittle once it is already cured. At relatively high temperature, the phenolic resin chars, namely, carbonized, and then ablates into carbon dioxide [30]. In addition, the cellulose fibers may also be oxidized at high temperature which eventually detach from the composite. As a result, the density of adhesion joints formed by the resin decreases and the porosity of the material may increase [31], thus changing the structure and the mechanical properties of the material. Maeda and Murakami [32] report that the shear strength of the friction material decreases due to thermal degradation, which affirms the aforementioned hypothesis.

\section{Conclusions}

Adhesive wear and thermal degradation are the main aging mechanisms in paper-based friction materials. These two degradation mechanisms (however, nonseparable) are inevitably present in practice, where the dominance depends on the operating condition. Although many studies concerning the tribological behavior of this material have been 
reported in the literature, the effects of each degradation mechanism on the frictional characteristics are not fully understood. In this paper, the respective influences of these two mechanisms have been investigated independently. The experimental results show that these two mechanisms have opposite influences on the frictional characteristics of paperbased materials. In general, the coefficient of friction (COF) increases with the progression of adhesive wear, mainly caused by the change of the surface topography; that is, the real contact area and number of asperities making contact increase in size. On the contrary, the COF decreases with the progression of thermal degradation, that is believed to be caused by the change of the structure and properties of the material.

\section{Appendix}

Let us consider a contact between two (nominally flat) discs subjected to a normal load $W$ as illustrated in Figure 14. It is assumed that the surface of the upper disc is smooth and the lower one is rough. Without loss of generality, suppose that the disc with rough surface is hollowed, that is, ring, where the inner and outer diameters are $d_{i}=2 r_{i}$ and $d_{o}=2 r_{o}$, respectively. The nominal contact area $A$ established between the two discs is $A=\pi\left(r_{o}^{2}-r_{i}^{2}\right)$. Under the assumption that the normal load $W$ is uniformly distributed across the average contact surface, hence, the average contact pressure $p$ can be expressed as

$$
p=\frac{W}{\pi\left(r_{o}^{2}-r_{i}^{2}\right)} .
$$

Inspection of the hatched (infinitely small) zones with each area of $d A$, the resulting friction torque $d M$ can be computed according to the following equation:

$$
d M=2 r d Q
$$

with $d Q$ denoting the resulting friction force of the hatched area $d A$. From the law of friction, the resulting friction force $d Q$ is expressible as

$$
d Q=\mu p d A,
$$

where $\mu$ denotes the coefficient of friction (COF). Substituting of (A.3) into (A.2) and by knowing that $d A=(r d \varphi) d r$, one will obtain

$$
d M=2 \mu p r^{2} d r d \varphi .
$$

Furthermore, by integrating the right and left terms in (A.4) and rearranging it, the $\mathrm{COF} \mu$ can be expressed as

$$
\mu=\frac{\int_{0}^{M_{f}} d M}{2 p \int_{r_{i}}^{r_{o}} r^{2} d r \int_{0}^{\pi} d \varphi .}
$$

Solving (A.5) and substituting the pressure $p$ expressed above to the latter equation, one can finally write the $\mathrm{COF} \mu$ as

$$
\mu=\frac{3 M_{f}\left(r_{o}^{2}-r_{i}^{2}\right)}{2 W\left(r_{o}^{3}-r_{i}^{3}\right)} .
$$

\section{Nomenclature}

$t: \quad$ Time

$\omega: \quad$ Sliding rotational velocity

$\theta: \quad$ Angular displacement

$v$ : $\quad$ Sliding velocity

$d_{i}, d_{o}$ : Inner and outer diameters of lining

friction material

$d_{m}: \quad$ Mean diameter of lining friction material

$r_{i}, r_{o}:$ Inner and outer radii of lining friction material

$p: \quad$ Pressure

$W: \quad$ Normal load

$M_{f}:$ Friction torque

Q: $\quad$ Friction force

$\mu$ : Instantaneous coefficient of friction

$\mu_{s}:$ Static coefficient of friction

$\mu_{k}: \quad$ Kinetic coefficient of friction

$\mu_{s}^{\text {ref }}:$ Static coefficient of friction at initial state

$\mu_{k}^{\text {ref }}: \quad$ Kinetic coefficient of friction at initial state

$\bar{\mu}_{s}: \quad$ Normalized static coefficient of friction

$\bar{\mu}_{k}: \quad$ Normalized kinetic coefficient of friction

A: Nominal/apparent contact area

$A_{r}: \quad$ Real contact area

$\phi(z)$ : Probability distribution function of the surface profile

$R_{a}: \quad$ Surface roughness

$R_{\mathrm{sk}}:$ The skewness of surface asperity heights distribution.

\section{Acknowledgments}

The authors wish to thank Dr. Mark Versteyhe of Dana Spicer Off-Highway Belgium for the experimental support. Technical assistance of Dr. Thierry Janssens is gratefully acknowledged. Valuable comments of Prof. Farid Al-Bender on this study are appreciated.

\section{References}

[1] Y. Enomoto and T. Yamamoto, "New materials in automotive tribology," Tribology Letters, vol. 5, no. 1, pp. 13-24, 1998.

[2] D. Chan and G. W. Stachowiak, "Review of automotive brake friction materials," Proceedings of the IME Part D, vol. 218, no. 9, pp. 953-966, 2004.

[3] B. K. Satapathy and J. Bijwe, "Composite friction materials based on organic fibres: sensitivity of friction and wear to operating variables," Composites Part A, vol. 37, no. 10, pp. 1557-1567, 2006

[4] K. Ito, K. A. Barker, M. Kubota, and S. Yoshida, "Designing paper type wet friction material for high strength and durability," SAE Technical Paper 982034, 1998.

[5] I. J. Selikoff, J. Churg, and E. C. Hammond, "Asbestos exposure and neoplasia," Journal of the American Medical Association, vol. 252, no. 1, pp. 91-95, 1984. 
[6] J. LaDou, “The asbestos cancer epidemic," Environmental Health Perspectives, vol. 112, no. 3, pp. 285-290, 2004.

[7] P. W. J. Bartrip, "History of asbestos related disease," Postgraduate Medical Journal, vol. 80, no. 940, pp. 72-76, 2004.

[8] J. Bijwe, "Composites as friction materials: recent developments in non-asbestos fiber reinforced friction materials - A review," Polymer Composites, vol. 18, no. 3, pp. 378-396, 1997.

[9] S. Ohkawa, T. Kuse, N. Kawasaki, A. Shibata, and M. Yamashita, "Elasticity-an important factor of wet friction materials," SAE Technical Paper 911775, 1991.

[10] H. Ito, K. Fujimoto, M. Eguchi, and T. Yamamoto, "Friction characteristics of a paper-based facing for a wet clutch under a variety of sliding conditions," STLE Tribology Transactions, vol. 36, no. 1, pp. 134-138, 1993.

[11] T. Matsumoto, "A study of the influence of porosity and resiliency of a paper-based friction material on the friction characteristics and heat resistance of the material," SAE Technical Paper 932924, 1993.

[12] T. Matsumoto, "Study of the durability of a paper-based friction material influenced by porosity," Journal of Tribology, vol. 117, no. 2, pp. 272-278, 1995.

[13] H. Gao and G. C. Barber, "Microcontact model for paper-based wet friction materials," Journal of Tribology, vol. 124, no. 2, pp. 414-419, 2002.

[14] Y. Kimura and C. Otani, "Contact and wear of paper-based friction materials for oil-immersed clutches-wear model for composite materials," Tribology International, vol. 38, no. 11-12, pp. 943-950, 2005.

[15] J. Fei, H. J. Li, L. H. Qi, Y. W. Fu, and X. T. Li, “Carbon-fiber reinforced paper-based friction material: study on friction stability as a function of operating variables," Journal of Tribology, vol. 130, no. 4, Article ID 041605, 2008.

[16] R. A. Lamport, J. M. Biermann-Weaver, V. K. Jain, and P. T. K. Shih, "Resin mixture for friction materials," US Patent no. 5.753.018, 1998.

[17] J. Fei, H. J. Li, Y. W. Fu, L. H. Qi, and Y. L. Zhang, "Effect of phenolic resin content on performance of carbon fiber reinforced paper-based friction material," Wear, vol. 269, no. 78, pp. 534-540, 2010.

[18] R. C. Lam and M. A. Yesnik, "Fibrous base material for a friction lining material comprising less fibrillated aramid fibers and synthetic graphite," US Patent no. 5.707.905, 1998.

[19] S. Li, M. Devlin, S. H. Tersigni, T. C. Jao, K. Yatsunami, and T. M. Cameron, "Fundamentals of Anti-Shudder Durability-Part I-Clutch Plate Study," SAE Technical Paper 2003-01-1983, 2003.

[20] K. Matsuo and S. Saeki, "Study on the change of friction characteristics with use in the wet clutch of automatic transmission," SAE Technical Paper 972928, 1997.

[21] Y. Yang and R. C. Lam, "Theoretical and experimental studies on the interface phenomena during the engagement of automatic transmission clutch," Tribology Letters, vol. 5, no. 1, pp. 57-67, 1998.

[22] W. Ost, P. De Baets, and J. Degrieck, "The tribological behaviour of paper friction plates for wet clutch application investigated on SAE\#II and pin-on-disk test rigs," Wear, vol. 249, no. 5-6, pp. 361-371, 2001.

[23] M. Ingram, H. Spikes, J. Noles, and R. Watts, "Contact properties of a wet clutch friction material," Tribology International, vol. 43, no. 4, pp. 815-821, 2010.
[24] T. Janssens, Dynamic characterisation and modelling of dry and boundary lubricated friction for stabilisation and control purposes [Ph.D. thesis], Katholieke Unversiteit Leuven, Department of Mechanical Engineering, Division PMA, Leuven, Belgium, 2010 .

[25] Y. R. Jeng and C. C. Gao, "Changes of surface topography during wear for surfaces with different height distributions," Tribology Transactions, vol. 43, no. 4, pp. 749-757, 2000.

[26] P. Nyman, R. Mäki, R. Olsson, and B. Ganemi, "Influence of surface topography on friction characteristics in wet clutch applications," Wear, vol. 261, no. 1, pp. 46-52, 2006.

[27] F. Al-Bender, V. Lampaert, and J. Swevers, "A novel generic model at asperity level for dry friction force dynamics," Tribology Letters, vol. 16, no. 1-2, pp. 81-94, 2004.

[28] F. Al-Bender and J. Swevers, "Characterization of friction force dynamics," IEEE Control Systems Magazine, vol. 28, no. 6, pp. 64-81, 2008.

[29] M. Ingram, J. Noles, R. Watts, S. Harris, and H. A. Spikes, "Frictional properties of automatic transmission fluids-part II-origins of friction-sliding speed behavior," Tribology Transactions, vol. 54, no. 1, pp. 154-167, 2010.

[30] R. A. Lamport, J. M. Biermann-Weaver, V. K. Jain, and P. T.K. Shih, "Resin mixture for friction materials," U.S. Patent No. 5.753.018, 1998.

[31] N. Chiba, M. Kano, and M. Inoue, "Mechanism of compression fatigue of wet friction materials," JSAE Review, vol. 22, no. 2, pp. 169-174, 2001.

[32] M. Maeda and Y. Murakami, "Testing method and effect of ATF performance on degradation of wet friction materials," SAE Technical Paper 2003-01-1982, 2003. 

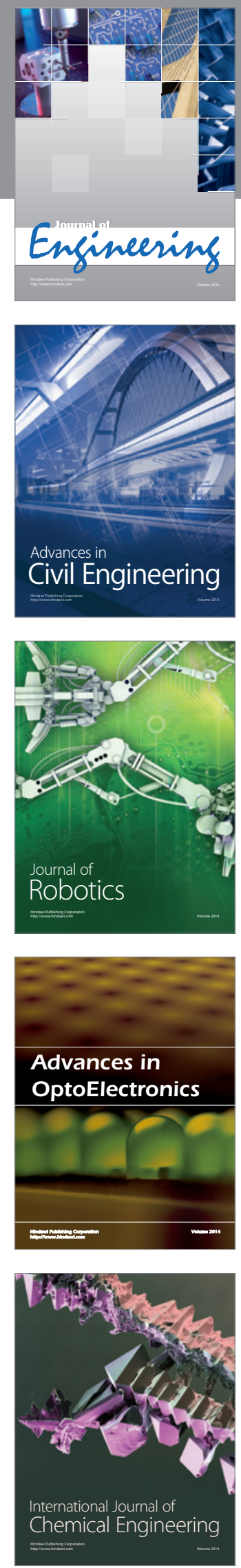

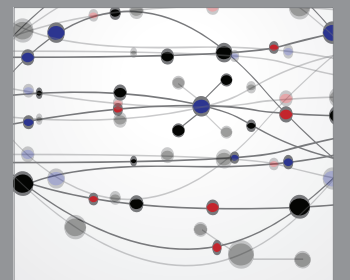

The Scientific World Journal
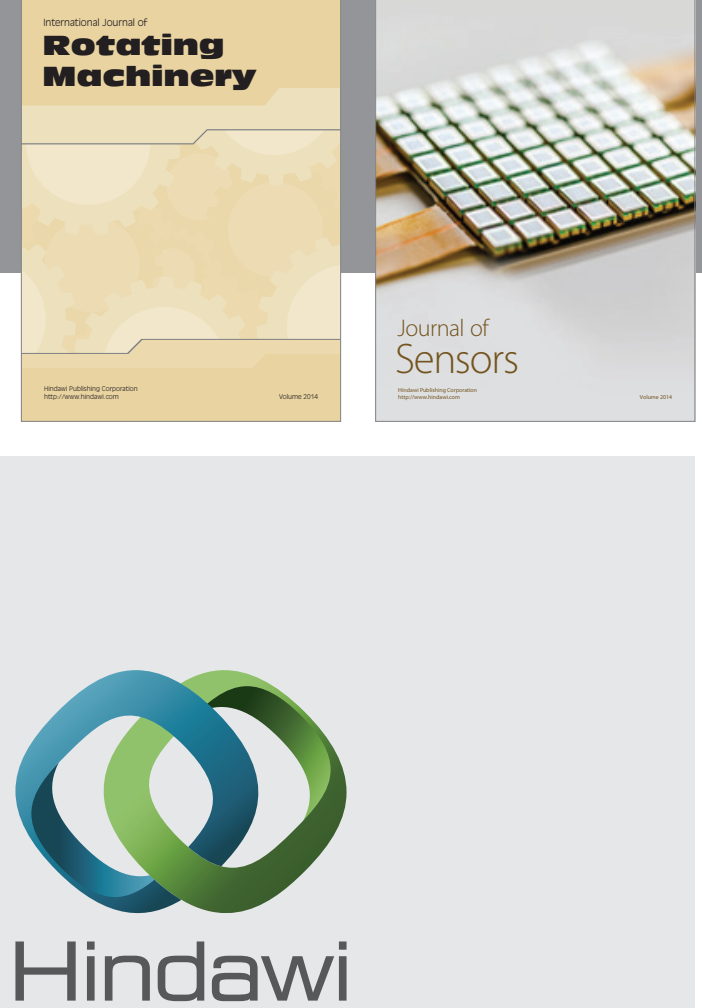

Submit your manuscripts at http://www.hindawi.com
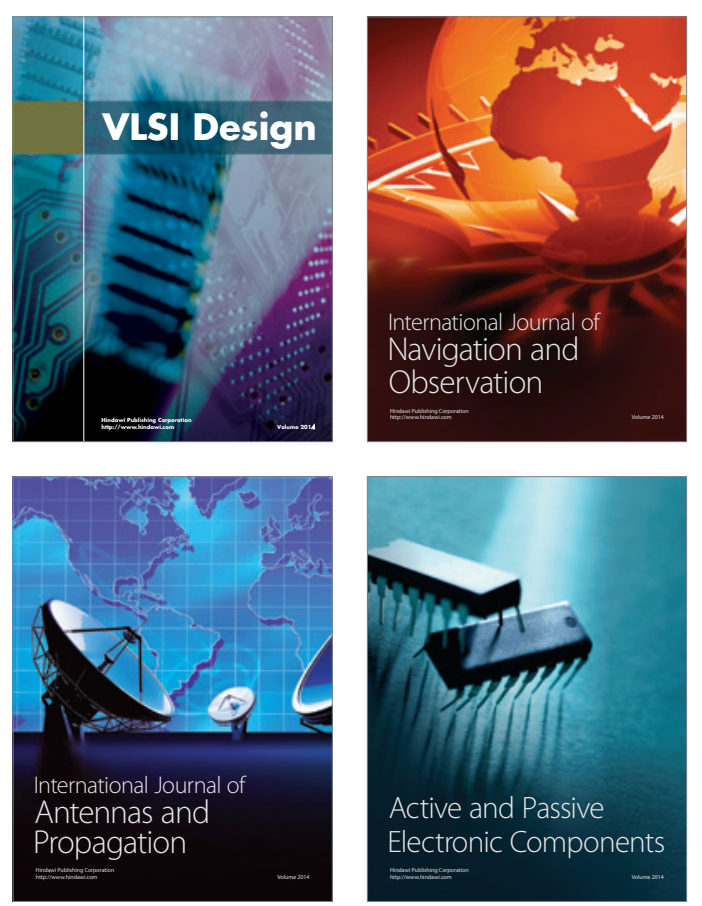
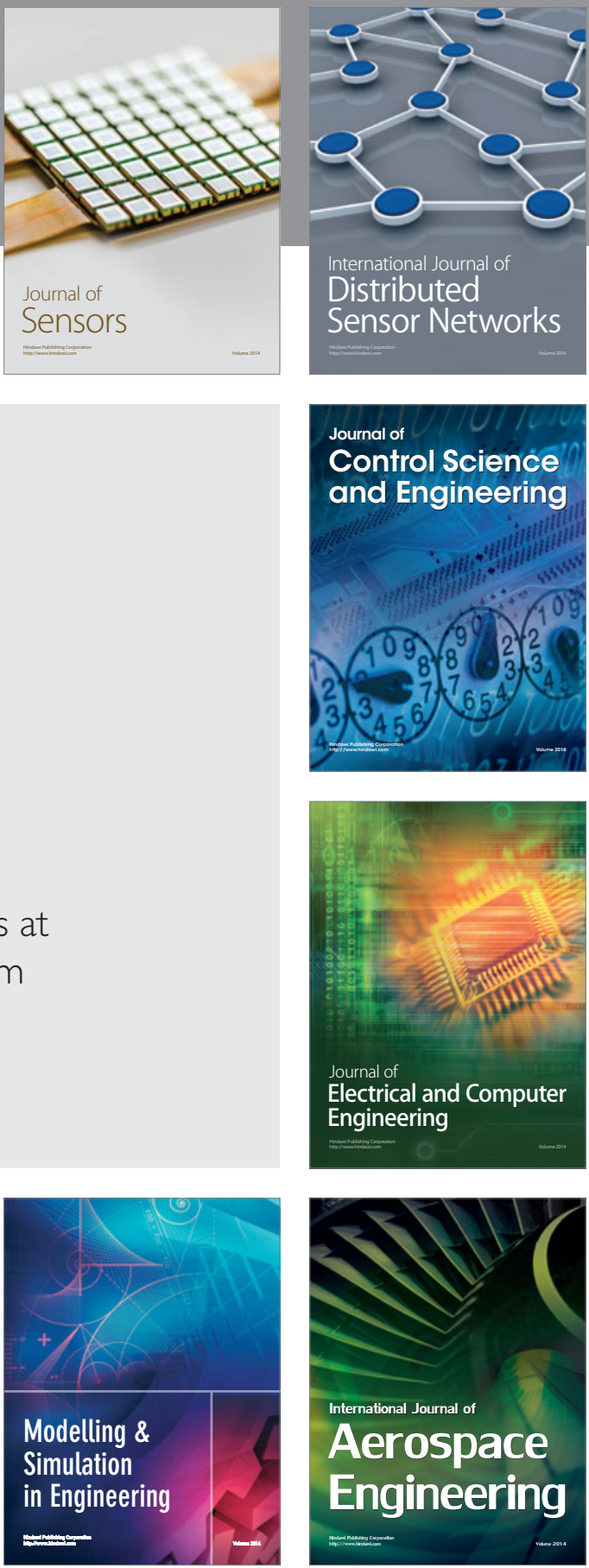

Journal of

Control Science

and Engineering
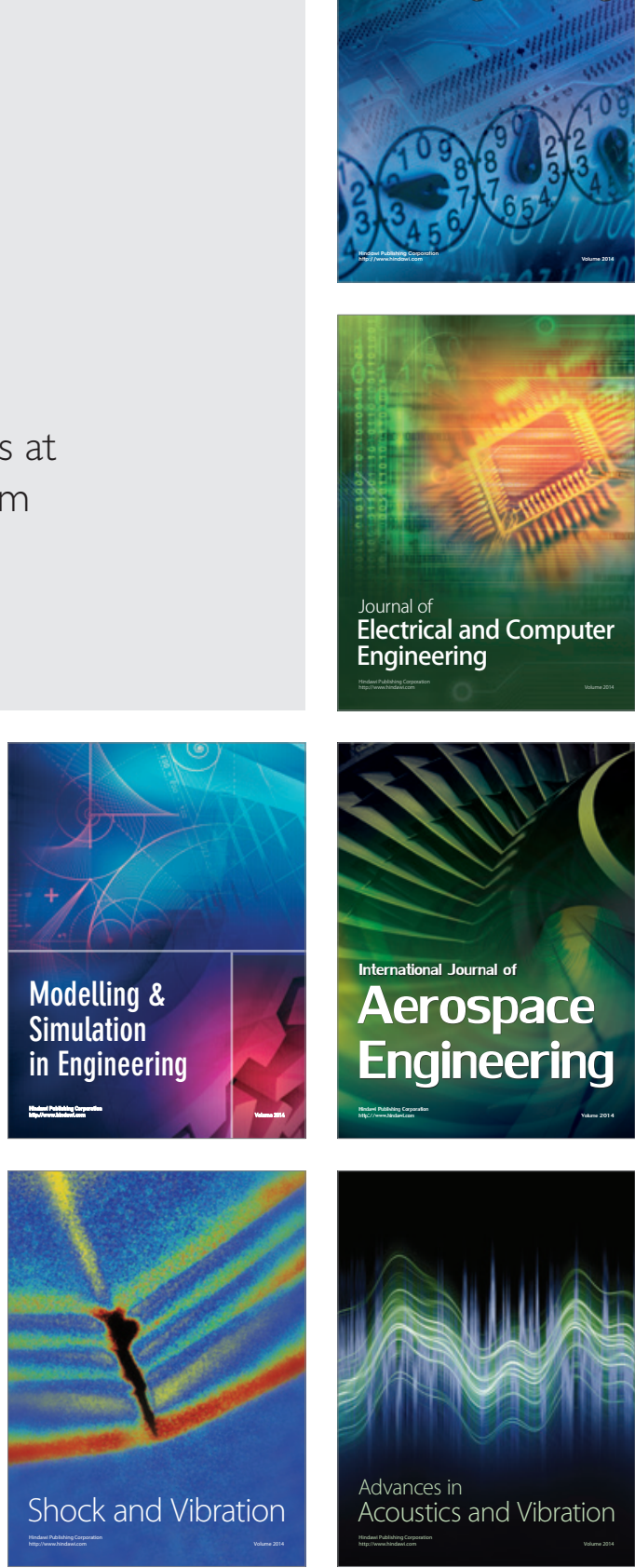